\title{
Excellence in teaching and learning: Students' perspective
}

\author{
Maya Shaha', ${ }^{1}$, J anet Berg ${ }^{3}$, J ennifer Wenzel ${ }^{3}$, J odi Shaefer ${ }^{3}$, Mary Terhaar ${ }^{3}$, Rachel Klimmek ${ }^{3}$, \\ Krystal C. Melvin ${ }^{4}$, Anne E. Belcher ${ }^{3}$ \\ 1. Department of Nursing Development \& Research, Inselspital, Bern University Hospital, Switzerland. 2. Institute of \\ Higher Education and Research in Nursing, University of Lausanne, Switzerland. 3. School of Nursing, Johns Hopkins \\ University, Baltimore, USA. 4. Center for Nursing Science and Clinical Inquiry Madigan Army Medical Center (MAMC), \\ Tacoma, USA.
}

Correspondence: Maya Shaha, PhD, RN. Address: Inselspital, Bern University Hospital, Department of Nursing Development \& Research, Freiburgstrasse, CH-3010 Berne, Switzerland. Email: Maya.Shaha@insel.ch.

Received: February 24, 2013

Accepted: May 1, 2013

Online Published: May 7, 2013

DOI : $10.5430 /$ jnep.v3n12p35

URL: http://dx.doi.org/10.5430/jnep.v3n12p35

\section{Abstract}

Background: Excellence in teaching and learning (ETAL) constitute important aims of nursing schools. At present, these aims are measured by course evaluations, students' passing rate of NCLEX exams (in the United States), graduate' students' employment rate, and positions, and graduates' continuing with post-graduate education. In order to continue improving ETAL in nursing schools, it is necessary to explore this phenomenon more fully.

Methods: A qualitative study using a community-based participatory research design was conducted at a leading nursing school in the U. S. In three phases, the perspectives of the students (phase one) and of the faculty (phase two) were elicited, as well as a model for ETAL developed (phase three). Students' views on barriers and facilitators to ETAL were obtained in focus groups. Faculty were interviewed. The model development involved inductive, as well as retroductive theory development strategies. Focus group and interview data were analysed using thematic analysis.

Results: In this manuscript, the results from phase one will be reported. A total of 41 students (bachelor, Masters and doctoral) participated in this phase. Three main themes were identified: Teaching excellence, Learning excellence, and Nursing as a new language. Students highlighted the need for congruence and coherence between the course syllabus and course assignments as essential contributors to teaching excellence. The supportive environment existing at the school was appreciated as it contributed substantially to learning excellence. Finally, the students highlighted that the clinicals were the most important elements in the curriculum. Clinicals allowed for an immersion in the practice field and, thus, were the most important way of learning Nursing as a new language.

Conclusions: The findings of the study's phase one have been taken into consideration by the newly developed Office for Teaching Excellence (OTE). A number of supportive measures for faculty have been developed and are on offer to faculty. Programs were improved in order to better support students in their learning excellence. Phase one of this study has highlighted that program coherence and congruence constitutes an important factor for excellence in teaching and learning.

\section{Key words}

Teaching and learning excellence, Cbpr, Focus groups 


\section{Introduction}

Ongoing changes in society, technology, manpower shortages and a financial crisis in healthcare demand new knowledge to maintain or improve quality and safety of the care given by healthcare providers (i.e., nurses, physicians, etc.). In response, nursing educators need to take these changes and challenges into account when preparing nursing students at baccalaureate, Masters and doctoral level. Appropriate educational techniques and approaches based on evidence need to be identified and implemented to provide high quality education ${ }^{[1-3]}$. Addressing the challenges facing nursing education will, it is hoped, improve the attraction of the profession and lead to higher numbers of nursing graduates ${ }^{[1,4]}$. Raising the attractiveness of educational institutions offering nursing programs at the baccalaureate, Masters and doctoral levels by setting the bar at excellence is also viewed as increasing the visibility of and attention given to nursing. Faculty must understand and value excellence in teaching and in learning ${ }^{[3,5]}$. Teaching excellence contributes to the preparation of graduates who are skilled in the implementation and maintenance of evidence-based nursing in practice, thereby providing higher quality of nursing care ${ }^{[1]}$.

\section{Background}

Implementing innovative curricula requires a clear aim for excellence, evidence-based evaluation strategies, faculty development, attention to student learning needs and implementation of effective teaching strategies with which to address these needs ${ }^{[6-8]}$. Research has demonstrated that students excel in learning if courses are well prepared and structured. If the learning environment is interactive and contains a balance among various pedagogies such as lecturing, web-based learning, seminars, skills laboratories, and clinical experiences, it is conducive to satisfying students' learning needs ${ }^{[7,9,10]}$. However, a lack of understanding of barriers and facilitators limit attainment of the goal of teaching excellence.

Currently, identification of teaching excellence in courses and programs relies heavily on student course evaluation ${ }^{\text {[11] }}$. However, it is questionable whether course evaluations, which are based primarily on the delivery of the course content and completed by students, can reliably and adequately capture the complexity of teaching excellence ${ }^{[12,13]}$. Rarely have course evaluations established reliability and validity; yet this level of measurement is often the gold standard to determine both teaching and program effectiveness. As noted in ref.14, "The evaluation of teaching and specific teaching strategies is value laden, fraught with concern and often discontent, and assigned a variety of adjectives and adverbs to describe the effects it has on both a teaching and a student” ${ }^{[14]}$. Research has demonstrated that comprehensive evaluation of teaching can lead to significant change and improvement ${ }^{[7,12,13]}$.

Excellence in teaching and learning is often determined by students' outcomes such as the pass rate on the NCLEX examination, the percentage of graduates' obtaining professional nursing positions, and the number of graduates pursing graduate study, or the amount of research funding a school can obtain. Although valuable and accessible metrics, these outcomes are imprecise and do not directly relate to the teaching-learning experience. As a result, these outcomes do not provide the real-time input and feedback needed to update and revise teaching strategies to meet students' learning needs and to achieve excellence in teaching and learning. The National League for Nursing has recognised this dilemma and has launched a think tank effort. The task group has proposed a list of questions that help identify excellence in teaching ${ }^{[6]}$. In response to these statements and to better understand teaching and learning excellence, Lerret and Frenn ${ }^{[15]}$ and Benner, Sutphen, Leonard, and Day ${ }^{[16]}$ conducted qualitative studies with educators and students in nursing education to describe excellence in teaching and learning. Where Lerret and Frenn ${ }^{[15]}$ based their study on parts of the grounded theory approach to understand the student perspective, Benner et al. ${ }^{[16]}$ used a combination of ethnographic, interpretive and evaluative approaches to explore the educational institutions and the educators' perspective. According to the findings of Lerret and Frenn ${ }^{[15]}$, teaching excellence from the students' perspectives consists of educators' sound knowledge base, having a high motivation and passion for their teaching topic, being orientated towards the students and respecting them ${ }^{[15]}$. Benner et al. identified three major findings in the study: 
"1. U.S. nursing programs are very effective in forming professional identity and ethical comportment",[16].

Nursing programs are found to include a variety of suitable pedagogic strategies that promote the acquisition of professional identity and ethical comportment in future graduates. Benner et al. ${ }^{[16]}$ emphasise the integration of coaching and experiential learning.

"2. Clinical practice assignments provide powerful learning experiences, especially in those programs where educators integrate clinical and classroom teaching. ${ }^{[16]}$.

As a result of experiential learning, nursing students are exposed to professional work early in their education. The nursing programs include a stepwise movement from simple to complex learning for nursing students to familiarize themselves with the demand of nursing work and to gain experience in working with patients. Throughout the education trajectory, the students are assigned increasingly challenging work and work load. Thus, transition into nursing practice as graduates is facilitated.

"3. U.S. nursing programs are not generally effective in teaching nursing science, natural sciences, social sciences, technology and humanities." ${ }^{[16]}$.

Since the demands of nursing practice are increasing due to innovations and adaptive changes to demographic development ${ }^{[4]}$, nursing programs need to adapt. Instead of reconceptualising the program to include new knowledge, the nursing curricula are simply enlarged. More knowledge is currently transported in nursing programs within the same amount of time. Overcharged nursing education, according to Benner et al. ${ }^{[16]}$, leads to less effective teaching in the areas of sciences identified in finding 3.

Despite the fact that the studies by Benner et al. ${ }^{[16]}$ and Lerret and Frenn ${ }^{[15]}$ provide in-depth insight into teaching and learning excellence, course and program evaluation remain a contentious issue ${ }^{[12,13]}$. Similarly, planning and implementing courses and programs that have as their goal excellence in teaching are underused ${ }^{[13]}$. Previous research has predominantly focused on educators' and PhD-students' perspective. The perspective of baccalaureate and Masters students has rarely been solicited. This is surprising, given the fact that the majority of students at nursing schools include baccalaureate and Masters students. Exploring teaching and learning excellence in one nursing school that already is considered an excellent institution nationwide will provide more insight and understanding of excellence in teaching. Obtaining a better grasp on excellence in teaching and learning will help to address improvements in the curriculum, the environment and will allow for the identification of adequate characteristics for outcome evaluation. Therefore, a study was conceptualised to address the following questions:

- What does excellence in teaching and learning mean? What are the characteristics?

- What are the facilitators that promote and the barriers that inhibit excellence in teaching and learning in a leading nursing school in the U. S.?

\section{Methods}

\subsection{Research design}

The aim of this study was to explore excellence in teaching and learning as described by students and faculty at one institution that is annually recognized as a leading nursing school in the U. S. To explore the characteristics of excellence in teaching and learning, as well as facilitators that promote and barriers that inhibit excellence, a community-based participatory research (CBPR) approach was selected. CBPR is recommended to explore views and attitudes within a community to a given topic, as well as to identify barriers and facilitators for improvement concerning the given 
topic ${ }^{[17-19]}$. The CBPR-approach is grounded in action research, but incorporates project management elements ${ }^{[18]}$. With the selection of a CBPR-approach it is possible to consider the nursing school as a whole and, therefore, also include environmental issues as part of the exploration. In general, nine steps or phases are identified within a CBPR-approach as demonstrated by the figure below. There are two major project parts: a diagnostic and an implementation part. The diagnostic part includes five steps or phases, which aim at providing a comprehensive picture of the community and its needs and demands concerning a given topic. The remaining four steps/phases include the implementation of a program to address some of the needs and demands identified in the diagnostic part and the corresponding evaluation. The CBPR-approach, therefore, is highly practical as it helps to address all relevant issues concerning any given topic.

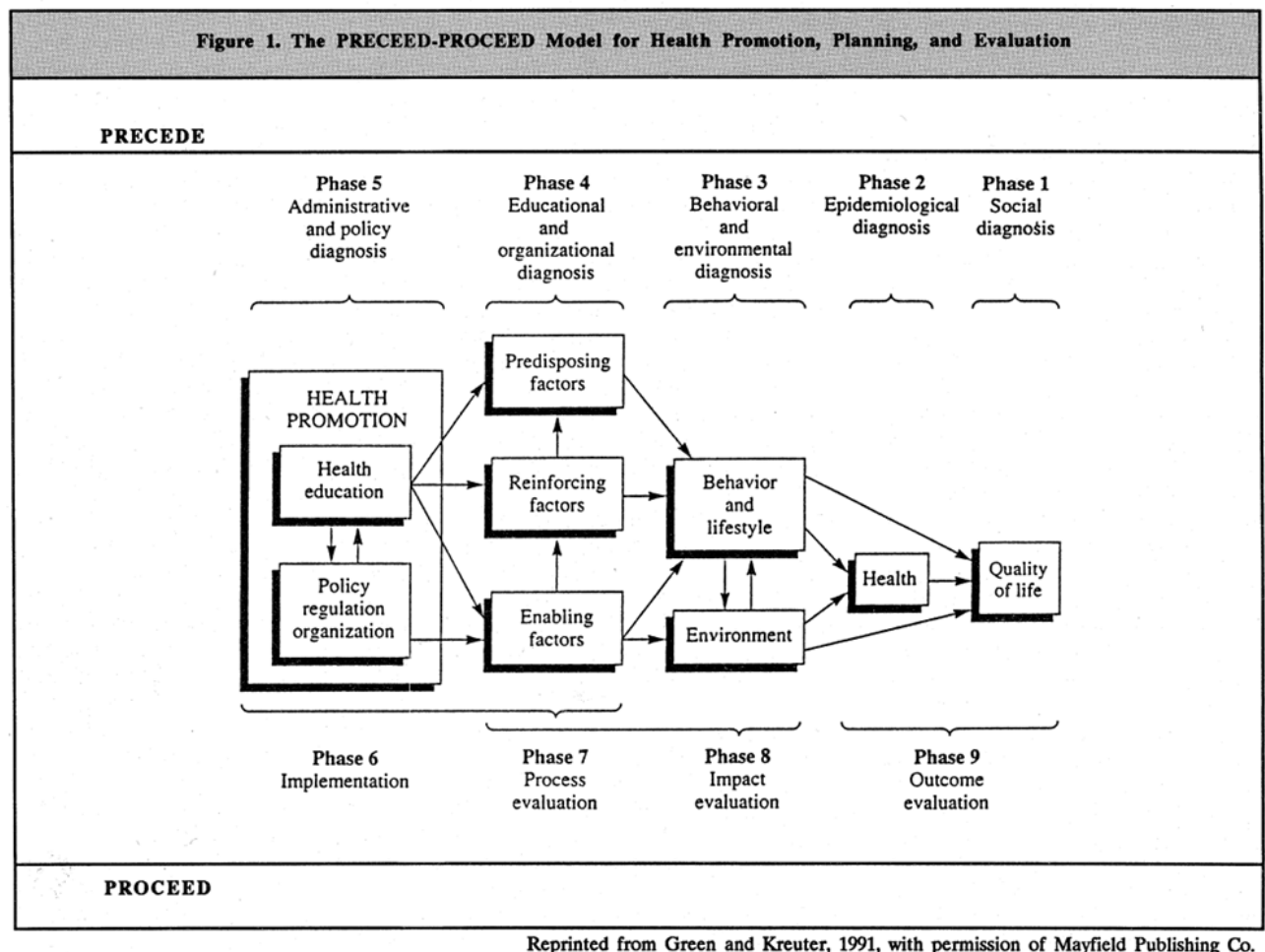

Figure 1. The Preceed-Proceed Model underlying CBPR.

[Picture drawn from Speziale and Carpenter $]^{[18]}$

In order to explore the excellence in teaching and learning within one particular nursing school, a research team was organized consisting of six members of the faculty of this school. Among these six faculty members were part-time, full-time faculty, as well as clinical faculty and post-doctoral students. In order to investigate the excellence in teaching and learning, a study was conceptualized consisting of three phases. The first phase aimed at eliciting the community's perspective on excellence in teaching and learning from students by using focus groups. The second phase was concerned with identifying specific aspects of teaching and learning excellence by using faculty interviews. Within the third and last phase the development of new supportive structures for faculty in preparing courses and course evaluations were planned. In this publication, the findings from the first phase will be reported. The findings from the second phase will be reported elsewhere. Conclusions from the third phase including the changes implemented in the organization as part of this study will also be reported elsewhere. Approval of the study was obtained from the institutional review board.

Ba focusing on the community's perspective on teaching and learning in the first phase of this study, the social, epidemiological, behavioral, environmental, educational and organizational diagnoses (see Figure 1) were elicited. The research group who had developed the research project, created a plan for informing all faculty, students and staff of the 
school about the project. Current data on the school's organizational structure, staff including faculty, students, and teaching/learning missions were gathered. Focus groups with students were conceptualized and promoted by flyers and e-mails, the research group and faculty of the school. Interested students were asked to signal their participation to the research group. The goal was to recruit at least 20 baccalaureate and Masters students as well as five doctoral students. The focus groups were scheduled to take place at lunch or at around 4 or 5 pm in the winter semester 2008/2009. Drinks and food were provided. On the one hand the nutrition served as an incentive. On the other hand providing drink and food was considered an important element to create a relaxed mood and environment. All focus groups were conducted by the post-doctoral student on the team as she was the least involved in teaching. All faculty of the research group were blinded to the students participating in the focus groups in order to reduce anxiety and to foster an open atmosphere. The students were aware of the faculty on the research team and were informed that none of the participants' names would be disclosed. All focus groups were tape recorded and transcribed verbatim. A total of seven focus groups were conducted with 20 bachelor, 10 Masters students and 11 PhD-students attending.

\subsection{Research environment}

This study was conducted at a large privately endowed, coeducational institution for higher education based in the U. S. At its opening in 1876, the university was the first educational institution in the U. S. established with advanced studies and research as its primary goals and, as such, it has been described as the first true university in America. This university is governed by a board of trustees with a current membership of 66 and comprises nine academic divisions. Among these is a school of nursing (SON). A new era of nursing education started at this university with the opening of this SON in the fall of 1984. The university's founder had identified a need for a training school for nursing in the original bequest to the university. Nursing education had been established at this time in the form of a hospital-based diploma program that opened in 1889. It enjoyed an international reputation for excellence in nurse training and a distinguished history. Due to the efforts of the nursing directors, the path was forged to move nursing training toward university education.

In 1982, at the request of the university's administration, a feasibility study was conducted resulting in the establishment of the SON in 1983 as the eighth academic division of the university. The SON was designed as an upper division baccalaureate program; the first class was accepted in 1984 and graduated in May 1986. The Master's program was established in 1987. Shortly thereafter, a doctoral program $(\mathrm{PhD})$ and the infrastructure for research were established. The Doctor of Nursing Practice (DNP) Program was approved in 2007 and admitted its first class in January 2008. The SON is accredited by the Collegiate Commission on Nursing Education (CCNE) and also receives continuing approval from the Maryland Board of Nursing. In fall 2011, the SON counted 70 full-time faculty and 69 part-time faculty. A total of 699 students were registered at that time.

\subsection{Analysis of focus group and interview data}

Two analytical periods occurred as the student focus groups were analyzed using a thematic and content analytical approach $^{[17,20]}$. The analytical process started with immersion in one focus group transcript and identification of codes and compiling categories. This first set of codes and categories was subsequently applied in a constant comparative process to the other focus group transcripts to identify similarities and dissimilarities regarding teaching and learning excellence, and barriers and facilitators. Based on these comparisons, the original set of codes and categories was adjusted. Member checking was included to enhance credibility ${ }^{[17]}$. The same process was applied to the transcripts of the faculty interviews.

\section{Results}

A total of seven focus groups were conducted, involving 41 students (bachelor, Masters and PhD). There were 34 female and seven male students. The majority of the students $(n=31)$ were Caucasian. Among all students, there were three Hispanic students, six students with an Asian background, and one African-American student. Mean age for the women was 32 and for the men 34 years. Overall, mean age was 32 years. 
A total of 20 baccalaureate students participated in the focus groups. Among these were four students completing a traditional baccalaureate program and 16 who were in the accelerated baccalaureate program. There were 10 Masters students, one of which was in the MSN/MPH program (Master of Nursing, Master of Public Health program). All others were studying in the nurse practitioner track. A total of ten PhD students and one DNP student participated in the focus groups.

Analysis of the data elicited four main categories. They are: Teaching excellence and requisite characteristics, Learning excellence and requisite characteristics, Nursing as a new language and Nursing education as a science.

\subsection{Teaching excellence}

For students teaching excellence includes well-structured curricula of taught courses and modules. The curriculum is perceived to be a map guiding the course with specific aims. These aims are expected to be represented in the course assignments due for this course. Otherwise the students considered such inconsistencies as lack of coherence and a source of confusion. Coherence was perceived to be evident in well-prepared courses. It follows that the course assignments are easily understandable and congruent with the course syllabus. Detailed course preparations in combination with congruent course assignments were considered the best basis for producing good work and obtaining high grades. Students' comments included the following:

"... it was like very clear and we had like a great well written assignment and we understood what the components of the assignment were. The assignment made sense so that like it built upon each other."

“... very clearly delineated objectives of what is expected and what you're supposed to learn, along with having those objectives very clearly discussed in the classroom."

Students observed that the organizational structure needs to be orientated toward teaching and learning excellence. Otherwise all measures may be in vain.

"...giving teachers the support that they need whether that is... hours to be able to do the grading, or like someone to help facilitate getting things up on the website. Or you know like things like that that help and I would say also then there performance is getting checked by the administrators. So that they know, like the director of the baccalaureate program knows what's going on in the classroom."

According to the students, it is important that the educator's expertise is evident. The students went as far as stating that an educator's expertise "cannot be questioned". Such knowledgeable educators were well received by the students as guides and support. Having clearly stated aims and objectives that are translated into course syllabi, course assignments and grading supports the notion of excellence and will contribute to better student performances. In addition, the organizational structure of the institution needs to provide sufficient supportive structures such as time for grading or additional help for large classes in order for teaching excellence to prosper.

\subsection{Learning excellence}

Students maintain that an excellent environment includes promoting structures for learning such as learning support. It is considered helpful if there are structures that allow student exchanges and collaborative learning areas.

"You know, our class set up a share site. And like there all these other lectures and everything else in other places that are there that are there to be able to really support and help you."

It is also maintained that the learning environment needs to foster collaboration and not competition. The latter is considered detrimental to learning excellence. 
"You know, I think that really in terms of a learning environment it absolutely has to be supportive and it cannot be competitive. And I think that is something that in terms of excellence in learning that there needs to be that environment."

From the students' point-of-view the educators sometimes forget that students are adults and can make decisions on their own. It is important that educators recognize the independence of students and support it instead of stifling it.

"I understand that sometimes teachers will worry: Well, we did that before and then we found students didn't come to class."

"But my attitude... goes back to: You know what? That's my problem... I'm old enough to decide what classes I go and what classes I skip. You know when I skip a class, it's not because I'm not at a bar having fun."

It is important for faculty to notice and include that students also bring resources to the table. In fact, if these can be accessed and used to support teaching or learning, excellence can be fostered.

\subsection{Nursing as a new language}

Students reflected on the fact that nursing school constituted something completely new. Starting a program in a school of nursing was different from any other experience the students had lived before. Some baccalaureate students observed that: "Learning nursing is analogous to the challenge of learning to speak a new language.” New students can feel overwhelmed at this new experience. Some students can even feel lost when the nursing school environment does not convey strong and noticeable foundation and grounding in this field. Students' comments included the following:

"That's kind of the difference between the baccalaureate and maybe more Master's thinking is that, this is an entirely new language to us. This is a very new way of thinking that I do need it explained to me."

"I mean to me it's very basic. The two plus two, all that stuff. All they need to do is give us the core words to describe what we're talking about. And we have the book. We can reference."

"...we are learning lots of things here and some of it is very challenging; new concepts, new ideas, and so I think that it's just like a spring board. They told us this before that just getting a spring board into nursing. That when we go into nursing whether it's a specialty or our field, there's lots more information to learn..."

This analogy was further extended to include cultural "immersion" (i.e., clinical experiences) and different units to learn the regional dialects, i.e., specialty procedures and their accompanying jargon and environments. As noted by one student:

"I think there's somewhat, at least during the first year of the course and maybe just all of the baccalaureate program, there doesn't seem to be an understanding among most of the professors and faculty that this really is a new language for us. I mean I know and we've eluded to it in the past, but like [she] was saying, people come from other careers, other degrees, other ways of thinking and nursing really is its own way of thinking. It's entirely new and after even two semesters of being immersed in that way of thinking it doesn't mean we're experts, because you really come in, you know, I know how to think and oh my goodness, I really don't know how to think about people when I have to evaluate them."

Another interesting observation came from a student who talked about excellence in terms of having a voice.

"I think as far as like excellence in the school like having you know, classes where you feel like you're actually heard and you actually like have a voice. Where there's not just you know like this huge lecture hall of you know of one hundred fifty people." 
In addition to supportive learning environments, receiving guidance about nursing as a science and profession also constitutes excellence.

\subsection{Nursing education as a science}

Students noted while reflecting on teaching that teachers and instructors needed to have an education on pedagogy and didactics. Without such specific teaching knowledge, it was deemed impossible to achieve teaching excellence. As noted by one student:

"I think though that's a lot of the problem I have with the focus being so much on every instructor being a PhD, a doctorally prepared, because they're not being doctorally prepared in how to teach. They're being doctorally prepared in their very limited field of expertise. And to, I almost feel like the baccalaureate program is like grade school, you know. And I understand that, but I do feel like any PhD on this floor could take our objectives, our PowerPoint, hook them into the computer, stand up there, give a basic lecture, maybe have a few questions, stop and maybe field them a little bit, and I would still go home with the same content."

Students noted that there seemed to be a lack of individualized input from instructors, along with the lack of preparation for teaching for most instructors. Faculty guidance in the journey toward knowledge discovery was, therefore, viewed as important.

"I think kind of a summary of what people have said also is that that fine balance as holding you accountable as a student for a certain amount, but also should you have any questions should you need to be; either if you need your hand held on a particular topic and really walk through it slowly. They are very tolerant of that; they really seemed to know; I know there's also models for teaching, but they will work with you on what you do know and help you slowly piece together the answers, so you're actually answering your questions or you're coming to that conclusion or you're practicing it in clinicals."

The students identified attributes conducive to or restrictive to learning. Innate attributes of teachers such as an approachable, professional attitude and being respectful towards the students were viewed positively. Similarly, selfawareness, creativity and courage in teachers were considered important. Teachers needed to provide a fundamental structure on which students can build and can develop. It was important to demonstrate such expertise and skill as well as fairness. Then it is possible for students to achieve individual growth, become flexible and develop adaptability. Students also evidence innate attributes such as self-directed learning, being open-minded and receptive to teaching. It was considered important to have the liberty of making mistakes and learn from them. Thus, students were able to experience “real-life learning”.

By contrast, students did not appreciate an attitude of "one-size fits all”. It was also considered detrimental if faculty was constantly in need of time or had a low commitment to teaching. Faculty shortage was also considered detrimental to successful implementation of excellence in teaching and learning. Similarly, overstressed faculty provided insufficient support. It was also deemed important to be challenged by and receive incentives for learning. Unprepared or unmotivated faculty was perceived to be problematic and a potential barrier to learning excellence.

In the graduate student group, an added level of translation of knowledge was introduced: the need for greater transfer of knowledge between clinicians and educators. Further, students identified the need to acknowledge and emphasize the importance of maintaining a connection between clinical settings and academic nursing faculty due to the necessary teaching/learning which are an inherent part of nursing practice. 


\section{Discussion}

This study used CBPR as design and aimed at eliciting student and faculty perspective of excellence in teaching and learning, as well as at developing a model of excellence in teaching in order to improve current teaching and moving toward excellence. Research about excellence in teaching is essential for schools of nursing. Excellence is perceived to offer the best way to enhance student learning experiences and of reducing the theory-practice gap ${ }^{[5,16,21]}$. Such research is perceived to guide schools in the implementation of their mission, which is to prepare nursing graduates who are ready to face the current and future challenges in healthcare. Results from studies eliciting the students and faculty's perspective of excellence will provide more detailed information about excellence criteria other than currently established ones such as NCLEX-passing rates. The phase one of this study included the perspective of all student groups that are currently registered in academic programs within the SON.

Based on the contributions of all participants, detailed perspectives on teaching and learning excellence were elicited. The students in this study highlighted the importance of coherence between course aims and syllabi as well the place of the course in the program. Issues about the development of adequate curricula and the challenges of bridging theory and practice have been addressed in other educational research. A large body of knowledge has ensued around the way to conduct teaching at the baccalaureate and Masters levels ${ }^{[2,3,12,13,15,22,23]}$. An important measure with which to improve the delivery of curricula is students' evaluation of faculty teaching. These evaluations are expected to provide answers about the content the students were able or unable to accommodate easily. Student evaluations also help faculty to develop new pedagogies that responded more effectively to student needs ${ }^{[2,3,9,24,25]}$. The students in this study did not specifically consider the course evaluations. However, the students indicated that faculty shortage or faculty with a low motivation for teaching or stressed were not conducive to learning excellence. For the students in this study, the clinical experience and the educators involved in the clinical experience were essential elements in the learning experience. The importance of the clinical experience has been recognized and implemented in the nursing curriculum in form of skills-lab ${ }^{[26]}$. However, the students in this study highlight the immersion in practice in form of clinicals as this provides the hands-on experience of patients and of the clinical practice culture.

Learning excellence is predominantly assessed and evaluated and reflected, presumably, by excellent grades. However, the students in this study point to a number of other areas that might be contributive to an excellent learning outcome. The students highlight the importance of a less competitive, more collaborative culture. Such attributes have been discussed in relation to problem-based learning and related theories ${ }^{[9,27-29]}$. The body of literature around critical thinking has also indicated the importance of personal reflection and discussion in groups to grasp complex and practice-related issues ${ }^{\text {[29-32] }}$.

Certainly a theme relevant to the baccalaureate students in this study is the one entitled "Nursing as a new language". Most of the students are new to nursing and, therefore, are at the outset of their socialization. Having a common language, understandable to all members of a particular field, is a characteristic of a profession and of a scientific discipline. Any new member of this field needs to be exposed to this new language and learn its terms, grammar and orthography. Only then can a new member eventually become a representative of this profession or scientific discipline ${ }^{[33-35]}$.

The last theme can be traced back to the Masters and doctoral students as they have the option of following a course of study on nursing education. Increasingly nursing has realized that the appropriation of nursing knowledge and its translation into nursing practice are essential features needed to improve bedside nursing. In particular, the incorporation of evidence-based nursing at the bedside requires that curricula include experiences in the evaluation and utilization of evidence-based practice and help nurses to understand the knowledge transfer and implementation process ${ }^{[36-40]}$. Otherwise, knowledge remains within a person and cannot be made available to other people concerned.

Other issues raised by the students led to changes in evaluation of teaching, development of new courses, and the creation of the Office for Teaching Excellence (OTE). Faculty leaders developed, pilot tested, and implemented a peer review system which enables faculty to seek classroom and/or clinical evaluation of their teaching by faculty colleagues trained to 
use an instrument created by a former faculty member. The data generated by the peer reviewers is shared with the faculty member being reviewed and is helpful to that individual in enhancing teaching effectiveness. The faculty member can also submit the peer review report in the promotion portfolio, which is required by the Appointments and Promotion Committee.

New online courses have been developed and implemented for preparation as a nurse educator (NECO). Both graduate students and faculty are eligible to enroll in one or more of these courses; satisfactory completion of four of these courses results in the awarding of a certificate of completion. Numerous students and faculty have completed the NECO and report great benefits to their effectiveness as teachers.

The OTE was created by the dean of the SON, with the goal of cultivating excellence in teaching. The services provided by the OTE include new faculty orientation, seminars and workshops about technology and other teaching strategies, instructional design support, financial support for research in nursing education, and awards for teaching excellence. The OTE has been very positively evaluated by faculty, who appreciate the school's tangible support of excellence in teaching.

This study includes a number of limitations, among which the long study period (over three years) is most notable. Reasons for this included an important time limitation due to the fact that the research group consists of four full-time faculty and two part-time faculty. Another reasons constituted the limited time resources of the participating faculty in this study's phase two. Time constitutes an important aspect in research and education ${ }^{[6,16]}$. Nevertheless, the study was completed and important findings have been translated into measures and interventions to guide education at the SON.

Another notable limitation is the qualitative approach employed in this study. The large study by Benner et al. ${ }^{[16]}$ also included a qualitative approach, i.e., a phenomenological approach. However, a participatory action-research approach was selected for this present study in order to address the SON as a community. Introducing change within an institution or another established entity necessitates that the social structures and other important aspects are recognized and addressed. Since one of the research group members is the Director of the OTE, the transfer of the acquired knowledge was facilitated and resulted in many interventions that are still being implemented.

A last important limitation is the inclusion of students' perception. Studies into the excellence of teaching have always included students' perspectives. However, doctoral students constituted the predominant groups that were included in past studies. Having baccalaureate and Masters students adding their voices to what is teaching and learning excellence has resulted in many interesting aspects that have not been highlighted in similar studies.

Excellence in teaching and learning continue to be important issues in nursing education, especially because of the impending faculty shortage, the persisting theory-practice gap and the existing nursing shortage. Because a qualitative approach was selected to explore excellence in teaching and learning, the inclusion of all levels of students has contributed to a wider perspective. It was possible to identify the importance of coherence between and among programs, syllabi, and courses as well as to highlight the important contribution of a more collaborative learning environment. The study has also resulted in a program of interventions to improve teaching and learning in order to achieve excellence. Further exploration is necessary to evaluate the obtained results.

Excellence in teaching includes not only the school ranking or the level of extra-mural funding, but also program coherence that leads to syllabi and courses that are meaningful to students. The students want to experience a 'learning moment' and to feel welcomed. Excellence in learning includes not only good grades but also an environment that fosters collaboration and reduces competition among students. Such approaches are expected to help students feel best prepared to be launched into professional life. 


\section{Acknowledgement}

We thank the SON for its support of this project. Most importantly we thank the students and the faculty members for having contributed with time and knowledge to this study. Another thank you goes to Ms J Warren.

\section{References}

[1] Aiken, L.H., Nurses for the future. New England Journal of Medicine, 2010; 364(3): 196-8. PMid:21158647 http://dx.doi.org/10.1056/NEJMp1011639

[2] Ironside, P.M., N. Diekelmann, and M. Hirschmann, Learning the practices of knowing and connecting: the voices of students. Journal of Nursing Education, 2005; 44(4): 153-5. PMid:15862047

[3] Ironside, P.M. and T.M. Valiga, How innovative are we? What is the nature of our innovation? Nursing Education Perspectives, 2007; 28(1): 51-3. PMid:17380961

[4] International Council of Nurses, Delivering quality, serving communities: nurses leading chronic care, in International Nurses Day, International Council of Nurses, Editor, 2010, International Council of Nurses: Geneva. 2010: 1-65.

[5] Ironside, P.M., Working together, creating excellence: the experiences of nursing teachers, students, and clinicians. Nursing Education Perspectives, 2005; 26(2): 78-85. PMid:15921123

[6] Hallmarks of excellence in nursing education. Nursing Education Perspectives, 2004; 25(2): 98-101. PMid:15124514

[7] Emerson, R.J. and K. Records, Today's challenge, tomorrow's excellence: the practice of evidence-based education. Journal of Nursing Education, 2008; 47(8): 359-70. PMid:18751650 http://dx.doi.org/10.3928/01484834-20080801-04

[8] Knos, S. and J. Gharrity, Creating a center for nursing excellence. JONA'S Healthcare Law, Ethics, \& Regulation, 2004; 6(2): 44-51; quiz 52-3. PMid:15387434 http://dx.doi.org/10.1097/00128488-200404000-00006

[9] Ironside, P.M., Trying something new: Implementing and evaluating narrative pedagogy using a multimethod approach. Nursing Education Perspectives, 2003; 24(3): 122-8. PMid:12830682

[10] Weaver, R.R., and J. Qi, Classroom Organization and Participation: College Students' Perceptions. Journal of Higher Education (Project Muse), 2005; 76(5): 570-601. http://dx.doi.org/10.1353/jhe.2005.0038

[11] Kaufman, K., Carnegie national survey of nurse educators: compensation, workload and teaching practice. Nursing Education Perspectives, 2007; 28(3): 164-167. PMid:17557639

[12] Arreola, R.A., Developing a comprehensive faculty evaluation system: a guide to designing, building, and operating large-scale faculty evaluation systems. 3rd edition. 2007, Bolton, MA: Anker. xxxi, 246 p.

[13] Chism, N.V.N. and G.W. Chism, Peer review of teaching: a sourcebook. 2nd edition. 2007, Bolton, MA: Anker. xvii, 209 p.

[14] Polifroni, E.C., Evaluating teaching strategies: a blended perspective. Journal of Nursing Education, 2008; 47(3): 95-7. PMid:18380261 http://dx.doi.org/10.3928/01484834-20080301-03

[15] Lerret, S.M. and M. Frenn, Challenge with care: reflections on teaching excellence. Journal of Professional Nursing, 2011; 27(6): 378-84. PMid:22142914 http://dx.doi.org/10.1016/j.profnurs.2011.04.014

[16] Benner, P.E., et al., Educating nurses: a call for radical transformation. 1st edition. The Jossey-Bass higher and adult education series. 2010, San Francisco, CA: Jossey-Bass. xx, 260 p.

[17] Denzin, N.K. and Y.S. Lincoln, The SAGE handbook of qualitative research. 3rd ed. 2005, Thousand Oaks, CA: Sage xix, 1210 p.

[18] Speziale, H.S. and D.R. Carpenter, Qualitative research in nursing: advancing the humanistic imperative. 4th ed. 2007, Philadelphia, PA: Lippincott Williams \& Wilkins. xvii, 477 p.

[19] Wallerstein, N.B. and B. Duran, Using community-based participatory research to address health disparities. Health Promotion Practice, 2006; 7(3): 312-23. PMid:16760238 http://dx.doi.org/10.1177/1524839906289376

[20] Tuckett, A.G., Applying thematic analysis theory to practice: a researcher's experience. Contemporary Nurse, 2005; 19(1-2): 75-87. PMid:16167437 http://dx.doi.org/10.5172/conu.19.1-2.75

[21] Hesketh, E.A., et al., A framework for developing excellence as a clinical educator. Medical Education, 2001; 35(6): 555-64. PMid:11380858 http://dx.doi.org/10.1046/j.1365-2923.2001.00920.x

[22] Ironside, P.M. and H.S. Speziale, Using evidence in education and practice: more findings from the national survey on excellence in nursing education. Nursing Education Perspectives, 2006; 27(4): 219-21. PMid:16921808

[23] Mailloux, C.G., The extent to which students' perceptions of faculties' teaching strategies, students' context, and perceptions of learner empowerment predict perceptions of autonomy in BSN students. Nurse Education Today, 2006; 26(7): 578-85. PMid:16571364 http://dx.doi.org/10.1016/j.nedt.2006.01.013

[24] Ironside, P.M., "Covering content" and teaching thinking: deconstructing the additive curriculum. Journal of Nursing Education, 2004; 43(1): 5-12. PMid:14748529 
[25] McKeachie, W.J., Student ratings: The validity of use. American Psychologist, 1997; 52(11): 1218-1225. http://dx.doi.org/10.1037/0003-066X.52.11.1218

[26] Kneebone, R.L., et al., Simulation and clinical practice: strengthening the relationship. Medical Education, 2004; 38(10): 1095-102. PMid:15461655 http://dx.doi.org/10.1111/j.1365-2929.2004.01959.x

[27] Oja, K.J., Using problem-based learning in the clinical setting to improve nursing students' critical thinking: an evidence review. Journal of Nursing Education, 2011; 50(3): 145-51. PMid:21210603 http://dx.doi.org/10.3928/01484834-20101230-10

[28] Sisk, R.J., Team-based learning: systematic research review. Journal of Nursing Education, 2011; 50(12): 665-9. PMid:22007709 http://dx.doi.org/10.3928/01484834-20111017-01

[29] Worrell, J.A. and J. Profetto-McGrath, Critical thinking as an outcome of context-based learning among post RN students: a literature review. Nurse Education Today, 2007; 27(5): 420-6. PMid:16945453 http://dx.doi.org/10.1016/j.nedt.2006.07.004

[30] Tanner, C.A., Nursing education: current themes, puzzles and paradoxes. Communicating Nursing Research, $2007 ; 40: 3-14$. PMid:17900063

[31] Turner, P., Critical thinking in nursing education and practice as defined in the literature. Nursing Education Perspectives, 2005; 26(5): 272-7. PMid:16295305

[32] Uys, B.Y. and S.M. Meyer, Critical thinking of student nurses during clinical accompaniment. Curationis, 2005; 28(3): 11-9. PMid:16245475 http://dx.doi.org/10.4102/curationis.v28i3.964

[33] Chinn, P.L. and M.K. Kramer, Theory and nursing: integrated knowledge development. 7th ed. 2007, St. Louis/MO: Mosby. xix, $265 \mathrm{p}$.

[34] Meleis, A.I., Theoretical nursing: development and progress. 4th ed. 2007, Philadelphia, PA: Lippincott Williams \& Wilkins. xix, $807 \mathrm{p}$.

[35] Rodgers, B.L., Developing nursing knowledge: philosophical traditions and influences. 2005, Philadelphia, PA: Lippincott Williams \& Wilkins. xvii, 228 p.

[36] Abrams, D.B., Applying transdisciplinary research strategies to understanding and eliminating health disparities. Health Education \& Behaviour, 2006; 33(4): 515-31. PMid:16769758 http://dx.doi.org/10.1177/1090198106287732

[37] Adams, S. and M.G. Titler, Building a learning collaborative. Worldviews on Evidence-Based Nursing, 2010; 7(3): 165-73. PMid:19804589 http://dx.doi.org/10.1111/j.1741-6787.2009.00170.x

[38] Rycroft-Malone, J., Theory and knowledge translation: setting some coordinates. Nursing Research, 2007; 56(4 Supplement): S78-85. PMid:17625479 http://dx.doi.org/10.1097/01.NNR.0000280631.48407.9b

[39] Schmalenberg, C., et al., Clinically competent peers and support for education: structures and practices that work. Critical Care Nurse, 2008; 28(4): 54-60, 62-5. PMid:18669707

[40] Rycroft-Malone, J. and T. Bucknall, Using theory and frameworks to facilitate the implementation of evidence into practice. Worldviews on Evidence-Based Nursing, 2010; 7(2): 57-8. PMid:20492634 